\title{
Transgenerational effects of land use on offspring performance and growth in Trifolium repens
}

\author{
Zhengwen Wang $^{1} \cdot$ Oliver Bossdorf $^{2} \cdot$ Daniel Prati $^{3} \cdot$ Markus Fischer $^{3,4}$. \\ Mark van Kleunen ${ }^{5}$
}

\begin{abstract}
Central European grasslands vary widely in productivity and in mowing and grazing regimes. The resulting differences in competition and heterogeneity among grasslands might have direct effects on plants, but might also affect the growth and morphology of their offspring through maternal effects or adaptive evolution. To test for such transgenerational effects, we grew plants of the clonal herb Trifolium repens from seeds collected in 58 grassland sites differing in productivity and mowing and grazing intensities in different treatments: without competition, with homogeneous competition, and with heterogeneous competition. In the competition-free treatment, $T$. repens from more productive, less frequently mown, and less intensively grazed sites produced more vegetative
\end{abstract}

Communicated by Jennifer A. Lau.

Zhengwen Wang

wangzw@iae.ac.cn

1 State Key Laboratory of Forest and Soil Ecology, Institute of Applied Ecology, Chinese Academy of Sciences, Shenyang 110164, China

2 Institute of Evolution and Ecology, Plant Evolutionary Ecology, University of Tübingen, Auf der Morgenstelle 5, 72076 Tübingen, Germany

3 Institute for Plant Sciences, University of Bern, Altenbergrain 21, 3013 Bern, Switzerland

4 Senckenberg Gesellschaft für Naturforschung, Biodiversity and Climate Research Centre BIK-F, Senckenberganlage 25, 60325 Frankfurt, Germany

5 Department of Biology, Ecology, University of Konstanz, Universitätsstrasse 10, Konstanz 78464, Germany offspring, but this was not the case in the other treatments. When grown among or in close proximity to competitors, $T$. repens plants did not show preferential growth towards open spaces (i.e., no horizontal foraging), but did show strong vertical foraging by petiole elongation. In the homogeneous competition treatment, petiole length increased with the productivity of the parental site, but this was not the case in the heterogeneous competition treatment. Moreover, petiole length increased with mowing frequency and grazing intensity of the parental site in all but the homogeneous competition treatment. In summary, although the expression of differences between plants from sites with different productivities and land-use intensities depended on the experimental treatment, our findings imply that there are transgenerational effects of land use on the morphology and performance of $T$. repens.

Keywords Competition · Foraging · Grazing · Mowing · Phenotypic plasticity

\section{Introduction}

The productivity and heterogeneity of grasslands are determined by the variation in climate, edaphic factors, and particularly by the land use in the area of interest (Adler et al. 2001; Zhou et al. 2008; Berner et al. 2011; Hirobe et al. 2013). In Central European grassland ecosystems, fertilization, mowing, and grazing are the primary land-use processes, and they are likely to affect the degree and heterogeneity of competition among plants. While fertilization and mowing may result in a spatially more homogeneous grassland sward, selective grazing and trampling by livestock can increase the temporal and spatial heterogeneity of soil nitrogen, light, and vegetation cover (Howe 1999; 
Augustine and Frank 2001; Bakker et al. 2003; Zhou et al. 2008; Marion et al. 2010). Thus, it is likely that ecological pressures on competitive ability, plastic foraging, and elongation responses of constituent plants vary among grasslands with different productivities and land-use types and intensities. These pressures might have direct effects on plants in these grasslands, but they may also affect the growth and morphology of their offspring through maternal effects and evolutionary change.

Clonal plants are common and often dominant in many ecosystems (de Kroon and Bobbink 1997; Klimeš et al. 1997). The success of clonal plants is often explained by specific traits (Fischer and van Kleunen 2002) such as selective ramet placement (i.e., clonal foraging; Wijesinghe and Hutchings 1997; Hutchings and Wijesinghe 2008), which may increase their competitive abilities or allow them to reduce or avoid competition in heterogeneous environments (van Kleunen and Fischer 2001). On the other hand, clonal plants can, just like non-clonal plants, also respond to shading from competitors through elongation responses (van Kleunen et al. 2000; Weijschedé et al. 2006, 2008b; Vermeulen et al. 2008; Bittebiere et al. 2012). However, whether-in addition to phenotypically plastic responses to competition and heterogeneity-there are also transgenerational effects on clonal plant traits is far from clear.

A recent meta-analysis showed that $60 \%$ of commongarden studies testing for evolutionary effects (or maternal carryover effects) of land use on plants in grasslands found differences between plants from sites with different landuse regimes (Pluess 2013). However, there were no general patterns in the direction of the differences, and it was not clear whether the differences that were found are adaptive (Pluess 2013). This lack of a general pattern could be partly due to the low number of studies for each comparison or to variation in growth conditions among studies. In highly productive grasslands, selection might generally favor competitive ability, and we may expect increased plant height and/or petiole lengths in order to avoid shading; on the other hand, in more heterogeneous grasslands with gaps in the vegetation, clonal foraging might be selected for, as it would allow the plants to occupy these gaps. The expression of differences among offspring may, however, depend on growth conditions (i.e., offspring may differ in plasticity). Therefore, to test whether differences among offspring in traits and plasticity might reflect adaptive transgenerational effects, plants from different land-use regimes should be grown under multiple environmental conditions simulating the different land-use regimes.

Here, we conducted a common-garden experiment in which we grew plants of the clonal herb Trifolium repens from seeds that had been collected in 58 grassland sites

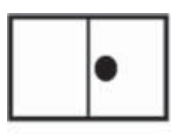

Homogeneous, no competition No comp - No comp

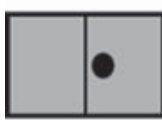

Homogeneous, competition Comp - Comp

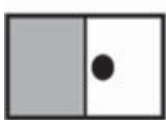

Heterogeneous, start without competition No comp - Comp

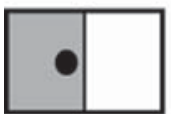

Heterogeneous, start with competition Comp - No comp

Fig. 1 Illustration of the design of the four experimental treatments. Gray indicates areas that were sown with competitors and black dots indicate the positions where seedlings of Trifolium repens were planted

differing in productivity and land use (mowing and grazing intensities). To test whether these plants differed in their responses to competitors, we grew half of them in experimental trays with or without competition. In addition, to test whether plants differ in their performance and capacity for foraging in heterogeneous environments, we grew the other half of the plants in trays with heterogeneous competition (Fig. 1). Here, the seedlings of T. repens were either planted just inside or outside the tray half with the competitors (simulating growth at the border of a vegetation gap created by livestock). We assessed petiole length as a measure of vertical foraging; preferential ramet placement in either of the two tray halves as a measure of horizontal foraging; and number of rooted rosettes, biomass, and flowering probability as measures of performance.

We asked the following specific questions. (1) Are plant performance and the response of this performance to experimental treatments related to the productivity and land-use intensity that the parental generation of these plants experienced in their grasslands of origin? We expected plants from more productive sites to show weaker negative responses to competitors. In addition, we expected plants from more intensively grazed sites, which are presumably more heterogeneous, to perform better under heterogeneous competition than plants from less intensively grazed sites. (2) Are vertical and horizontal foraging responses of plants related to the productivity and land-use intensity of the grasslands of maternal origin? We expected plants from more productive sites with high vegetation to produce long petioles, and plants from frequently mown sites to produce short petioles (to avoid damage by mowing). In addition, we expected plants from more intensively grazed (heterogeneous) sites to show stronger plastic foraging responses. 


\section{Materials and methods}

\section{Study species}

Trifolium repens is a common clonal herb occurring in a broad range of habitats, including pastures, roadside verges, and frequently flooded riverine habitats (Huber et al. 2009; Vermeulen and During 2010). During one growth season, a single plant of $T$. repens can produce up to 30 aboveground horizontal stems (stolons) that are used for clonal spread. This stoloniferous growth form is regarded as advantageous under grazing, and is thought to contribute to the persistence of the species in grasslands (Aasmo Finne et al. 2000). A stolon consists of a series of internodes, and each node can develop into a ramet consisting of one leaf and two root primordia, which can develop into primary roots. The axillary bud at each node can either form a lateral stolon or an inflorescence (Johansen 2009; Huber et al. 2009). Although clones of T. repens are highly integrated in terms of inter-ramet resource sharing, individual ramets are potentially independent, as they usually survive and produce stolons after they get disconnected with other ramets of the same clone (Huber et al. 2009). Therefore, the number of individual ramets produced by a clone is a good measure of the extent of vegetative reproduction.

\section{Seed material and pre-cultivation of plants}

The seeds of $T$. repens used in our experiment were collected during three sampling campaigns in June, July, and August 2008 from 58 grassland sites within the so-called Biodiversity Exploratories (Fischer et al. 2010). In each site, seeds were collected from 15 randomly chosen plants, separated by at least $1 \mathrm{~m}$, along four parallel transects (Völler et al. 2012). Seeds collected from different plants were kept separately, and are referred to as seed families. The Biodiversity Exploratories consists of three regions (exploratories): the Schwäbische Alb in southern Germany, Hainich-Dün in central Germany, and Schorfheide-Chorin in northern Germany (Table S1 in the Electronic supplementary material, ESM). In each of these exploratories, the grassland sites cover a wide range of land-use types and intensities, and have been well characterized with respect to productivity $\left(66-449 \mathrm{~g} \mathrm{~m}^{-2}\right)$ and land use (grazing: 0-1060 livestock units days ha ${ }^{-1}$ year $^{-1}$, mowing: 0-3 times year ${ }^{-1}$ and fertilizer application: $0-130 \mathrm{~kg} \mathrm{~N}$ year $^{-1}$, for details see Table S1 in ESM). Each site was used as grassland for at least 20 years prior to the establishment of the Biodiversity Exploratories, and data on productivity, mowing, and grazing are available from 2006 onwards. It is likely that the prior land-use regimes were quite similar to the post-2006 ones. There were 24 sampling sites in Schorfheide-Chorin, 14 in Hainich-Dün, and 20 in the Schwäbische Alb.
On 4-6 June 2010, we sowed 10-30 seeds of three randomly chosen seed families from each of the 58 populations (totaling 174 seed families) in separate 1.6-L trays filled with seedling soil and placed them in an uncontrolled glasshouse. We filled 696 experimental trays $(40 \times 24 \times 12 \mathrm{~cm})$ with a 1:1 mixture of sieved sand (0-4 $\mathrm{mm})$ and clay-rich agricultural soil and placed them in the garden next to the glasshouse. The 696 experimental trays were assigned to four blocks, separated by c. $1.5 \mathrm{~m}$, each consisting of three rows running north-south. In $25 \%$ of the trays per block, we sowed $0.70 \mathrm{~g}$ of a mixture of seeds from plants that are typical of nutrient-rich grasslands in Germany (Rieger-Hofmann GmbH, Blaufelden-Raboldshausen, Germany; see Table S2 of the ESM for the composition of the mixture) evenly throughout each tray (homogeneous competition treatment). In another $25 \%$ of the trays, we did not sow any competitors (homogeneous no-competition treatment). In the remaining half of the trays, we sowed $0.35 \mathrm{~g}$ of the seed mixture evenly in the western half of each tray (for the two heterogeneous competition treatments; see below). The sowing was done on 3-4 May 2010, c. two months prior to planting the $T$. repens seedlings. As the densities of the competitors were quite low, we added $0.60 \mathrm{~g}$ of seeds to the homogeneous competition trays (totaling $1.30 \mathrm{~g}$ per tray) and $0.30 \mathrm{~g}$ of seeds to the heterogeneous competition trays (totaling 0.65 g per tray) on 2-3 June 2010.

\section{Experimental setup}

From 28 June until 2 July 2010, we randomly assigned one seedling of each of the 174 seed families to each of the four experimental treatments. We planted the seedlings $2 \mathrm{~cm}$ from the center of each tray, which in the heterogeneous treatments meant that the seedlings were planted just inside or outside of the tray half with competition (Fig. 1). Thus, we had four treatment combinations based on whether the seedling immediately experienced competition (yes, no) and heterogeneity (yes, no; Fig. 1). As T. repens stolons and leaves are usually longer than $2 \mathrm{~cm}$, it is likely that plants in the heterogeneous trays were able to detect the neighboring tray halves with or without competition. The four experimental trays of the same seed family (one tray per treatment) were placed in the same block, but the three seed families of the same population were randomly assigned to three different blocks. We watered the trays as necessary to prevent them from drying out.

\section{Measurements}

Directly after the start of the experiment (i.e., after planting the $T$. repens seedlings into the experimental trays), we counted the number of leaves and measured the length of the longest leaf (i.e., combined length of petiole and 
leaf blade) on each $T$. repens seedling as measures of initial size. Six weeks after the start of the experiment, on 9 August 2010, we measured the length of the longest petiole on each originally planted ramet, henceforth called the mother ramet. Two weeks later, from 23 to 30 August 2010, we harvested all of the aboveground biomass of each plant and separated it into the mother ramet, the parts produced in the western half of the tray (in the heterogeneous treatments, this was the half with competitors) and the parts produced in the eastern half of the tray. We counted the number of rooted rosettes (i.e., daughter ramets), and recorded the presence of flowers in the eastern and western tray halves separately. Then we weighed the three parts of each plant separately after drying the plants to constant weight for more than $48 \mathrm{~h}$ at $70{ }^{\circ} \mathrm{C}$. The index of clonal foraging (i.e., selective ramet placement into one of the tray halves) was calculated as the difference in the number of rooted nodes between the western and eastern halves of each tray, divided by the sum of both (i.e., [west - east]/ [west + east]; e.g., Wang et al. 2013).

\section{Data analysis}

All morphological and performance variables were analyzed using generalized linear mixed effects models implemented in the lme4 package (Bates et al. 2012) in R version 2.15.2 (R Development Core Team 2012). For the analyses of petiole length, foraging index, and aboveground biomass (i.e., continuous response variables), we used a Gaussian error distribution. Aboveground biomass was lntransformed prior to analysis to fulfill the assumptions of normality and homoscedasticity. For the analysis of the number of rooted nodes (i.e., count data) and flowering status (binary data), we used a Poisson and a binomial error distribution, respectively.

To test for effects of land use in the parental sites on plant traits, we included productivity (biomass produced in $1 \mathrm{~m}^{2}$ of vegetation averaged across the years 2008-2010, see Socher et al. 2012), mowing intensity (the mowing index averaged across the years 2006-2010), and grazing intensity (the grazing index averaged across the years 2006-2010) as continuous explanatory variables in the fixed model. The mowing index was calculated as the frequency of mowing per year in a site divided by the average mowing frequency in the respective exploratory (Blüthgen et al. 2012). The grazing index was calculated for each site as the livestock-unit days $\mathrm{ha}^{-1}$ year $^{-1}$ divided by the average value of the respective exploratory (Blüthgen et al. 2012). To account for the fact that average land-use intensity values may have differed among the three exploratories, we also included exploratory identity (Schwäbische Alb, Hainich-Dün, Schorfheide-Chorin) as a fixed factor in the models before fitting the land-use indices. The grazing index was ln-transformed to get a more even distribution of values. To test for effects of the experimental treatments, we included the factors competition (mother ramet planted in a tray half with or without competition) and heterogeneity, as well as their interaction in the fixed model. To test whether the effects of land use in the parental sites depended on the experimental treatment, we included interactions of productivity, mowing intensity, and grazing intensity with the experimental treatments in the fixed model. In the analysis of petiole length, we accounted for initial differences in leaf length (i.e., combined length of petiole and leaf-blade) by including it as a covariate. In the analysis of performance variables, we accounted for initial differences in plant size by including initial size (measured as the product of the number of leaves and the length of the longest leaf) as a covariate. In addition, because both the planting and the harvesting took multiple days, meaning that some plants had more time to grow than others, we also included the time from start to harvest (duration of experiment) as a covariate. In the random model, we included block and seed family nested within population. In the analysis of the number of rooted nodes, we also included an observationlevel random effect to reduce overdispersion (Zuur et al. 2012). All covariates and continuous explanatory variables were scaled to a mean of zero and a standard deviation of 1 to facilitate interpretation of the results (Schielzeth 2010).

We used log-likelihood ratio tests to assess the significance of the fixed terms (Zuur et al. 2009). The three-way interactions were tested by comparing the log-likelihood of the complete model with those of the models from which the three-way interactions were removed in turn. The loglikelihood ratio is calculated as two times the difference in log-likelihood between a model and a submodel, and approximately follows a chi-squared distribution. The twoway interactions were tested by comparing the model without any three-way interactions with the model from which the two-way interactions were removed in turn. The main effects were tested by comparing the model without any interactions with the model from which the main effects were removed in turn.

\section{Results}

\section{Performance traits}

Plants in the homogeneous competition-free treatment produced the largest number of rooted rosettes, had the highest probability of flowering, and produced the most aboveground biomass (Fig. $2 \mathrm{a}-\mathrm{c}$ ). Plants in the other three treatments, irrespective of whether they were initially planted in a competition-free tray half or not, produced very few rooted rosettes, had a low flowering probability, 
Fig. 2 Response of $T$. repens performance and plasticity to experimental treatments. Bars are least-squares means $( \pm \mathrm{SE})$ of $\mathbf{a}$ the number of rooted offspring ramets, b flowering probability, $\mathbf{c}$ aboveground biomass, d petiole length of the longest leaf on the mother ramet, and e the clonal foraging index. $p$ values of the significant effects of competition (C), heterogeneity $(\mathrm{H})$, and their interaction $(\mathrm{C} \times \mathrm{H})$ are given in each graph (also see Tables 1,2)
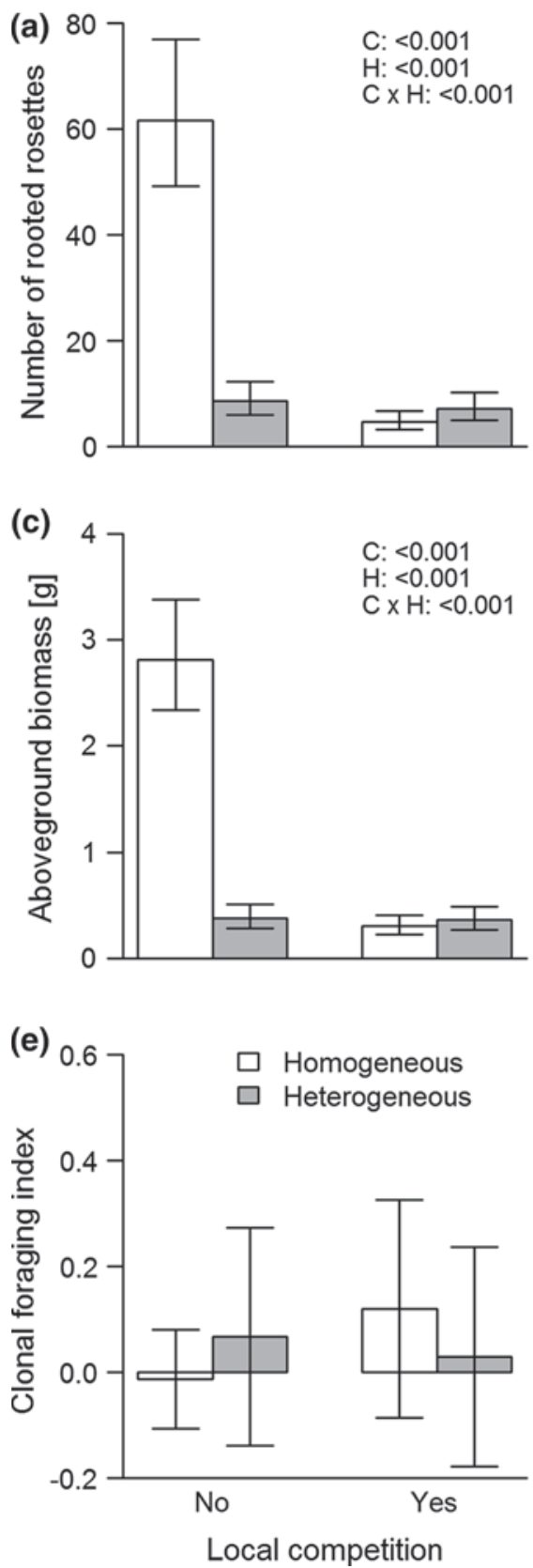
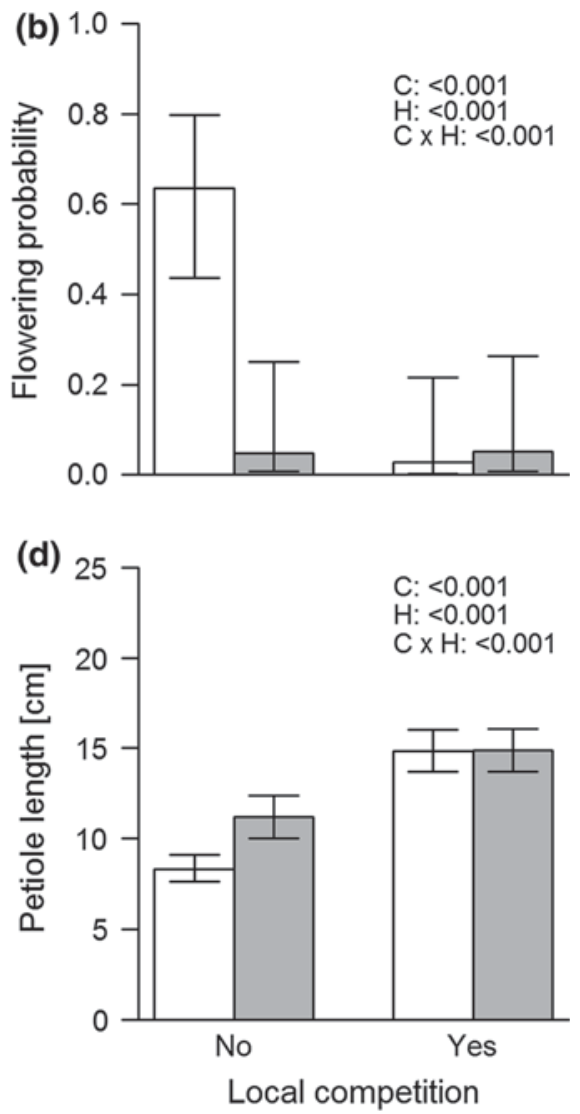

and produced little aboveground biomass (Fig. 2a-c). This was reflected in significant effects of competition, heterogeneity, and their interaction (Table 1).

In the competition-free treatment, the number of rooted rosettes tended to increase with the productivity of the site of origin (Fig. 3a), and decreased strongly with the mowing and grazing intensities of the site of origin (Fig. 3b, c). In the other three treatments, where the numbers of rooted rosettes were overall very low, these associations between number of rooted rosettes and the land-use variables were absent or weaker (Fig. 3). This dependency of the relationship between number of rooted rosettes and the land-use variables on the combination of the competition and heterogeneity treatments was reflected in significant three-way interactions between competition, heterogeneity, and the land-use variables (Table 1). The strong effects of mowing and grazing intensities in the competition-free treatment also resulted in significant main effects for mowing and grazing intensities (Table 1).

Flowering probability was not significantly affected by any of the land-use variables (Table 1). Aboveground biomass was also not affected by the productivity and grazing intensity of the site of origin (Table 1). However, while aboveground biomass increased with mowing intensity of the site of origin when plants grew in the homogeneous competition treatment or when they started in the 
Table 1 Results of (generalized) linear mixed models for two measures of offspring performance and aboveground biomass for plants of $T$. repens from grassland sites with different productivities and mowing and grazing intensities when growing under different competitive settings

\begin{tabular}{|c|c|c|c|c|c|c|c|}
\hline \multirow[t]{2}{*}{ Term } & \multirow[t]{2}{*}{$d f$} & \multicolumn{2}{|c|}{ No. of rooted rosettes } & \multicolumn{2}{|c|}{ Flowering probability } & \multicolumn{2}{|c|}{$\begin{array}{l}\text { Aboveground } \\
\text { biomass }\end{array}$} \\
\hline & & $\overline{\chi^{2}}$ & $P$ & $\overline{\chi^{2}}$ & $P$ & $\overline{\chi^{2}}$ & $P$ \\
\hline \multicolumn{8}{|l|}{ Fixed } \\
\hline Initial size & 1 & 55.77 & $<0.001$ & 3.51 & 0.061 & 74.62 & $<0.001$ \\
\hline Duration of experiment & 1 & 23.1 & $<0.001$ & 1.37 & 0.241 & 10.41 & $<0.001$ \\
\hline Exploratory & 2 & 3 & 0.223 & 6.44 & 0.04 & 1.73 & 0.421 \\
\hline Productivity & 1 & 0.04 & 0.845 & 0.11 & 0.746 & 2.62 & 0.106 \\
\hline Mowing intensity & 1 & 4.44 & 0.035 & 1.42 & 0.233 & 2.2 & 0.138 \\
\hline Grazing intensity & 1 & 6.18 & 0.013 & 0.46 & 0.497 & 0.7 & 0.403 \\
\hline Competition treatment & 1 & 301.5 & $<0.001$ & 88.42 & $<0.001$ & 277.95 & $<0.001$ \\
\hline Heterogeneity treatment & 1 & 135.2 & $<0.001$ & 101.88 & $<0.001$ & 204.42 & $<0.001$ \\
\hline Comp $\times$ hetero & 1 & 242 & $<0.001$ & 34.64 & $<0.001$ & 327.92 & $<0.001$ \\
\hline Comp $\times$ explo & 2 & 1.44 & 0.488 & 2.14 & 0.343 & 0.52 & 0.77 \\
\hline Comp $\times$ prod & 1 & 0.19 & 0.66 & 3.84 & 0.05 & 1.41 & 0.234 \\
\hline Comp $\times$ mow & 1 & 0.11 & 0.739 & 2.63 & 0.105 & 0.36 & 0.548 \\
\hline Comp $\times$ graz & 1 & 2.39 & 0.122 & 3.03 & 0.082 & 2.15 & 0.143 \\
\hline Hetero $\times$ explo & 2 & 0.68 & 0.712 & 0.63 & 0.732 & 0 & 1 \\
\hline Hetero $\times$ prod & 1 & 0 & 0.958 & 0.03 & 0.86 & 0 & 1 \\
\hline Hetero $\times$ mow & 1 & 0.46 & 0.497 & 0 & 0.948 & 0.01 & 0.926 \\
\hline Hetero $\times$ graz & 1 & 0.04 & 0.846 & 0.26 & 0.608 & 0.2 & 0.656 \\
\hline Comp $\times$ hetero $\times$ explo & 2 & 10.75 & 0.005 & 0.18 & 0.913 & 2.94 & 0.23 \\
\hline Comp $\times$ hetero $\times$ prod & 1 & 5.47 & 0.019 & 0 & 0.987 & 0 & 1 \\
\hline Comp $\times$ hetero $\times$ mow & 1 & 8.26 & 0.004 & 0.2 & 0.656 & 4.2 & 0.04 \\
\hline Comp $\times$ hetero $\times$ graz & 1 & 5.87 & 0.015 & 1.59 & 0.207 & 1.98 & 0.159 \\
\hline \multicolumn{8}{|l|}{ Random } \\
\hline Block & & 0.020339 & & 0.29888 & & 0.012622 & \\
\hline Population & & 0.002459 & & 0 & & 0.004942 & \\
\hline Seed family & & 0.079385 & & 0.511 & & 0.025288 & \\
\hline Residual/observation & & 0.412633 & & - & & 0.366537 & \\
\hline
\end{tabular}

For the fixed terms, $\chi^{2}$ values are given based on log-likelihood ratio tests. For the random terms, variances are given. Note that there is no residual variance for flowering probability as it has a binomial distribution competition-free tray half of the heterogeneous treatment, this relationship was weaker in the other two treatments (Fig. 4). This was reflected in a significant three-way interaction of competition, heterogeneity, and mowing intensity (Table 1).

\section{Vertical and horizontal foraging responses}

Mother rosettes had much longer petioles in tray halves with competition than in tray halves without competition, regardless of the distribution pattern of competitors within the trays (Table 2; Figs. 2d, 5). When mother rosettes were planted in tray halves without competition, they also had longer petioles when there were competitors in the neighboring tray half than when there were none (significant heterogeneity and competition $\times$ heterogeneity effects in Table 2; Figs. 2d, 5).
There were significant main effects of land-use variables on petiole length, but the magnitude of these effects depended on the growth environment (Table 2; Fig. 5). Plants from more productive sites produced longer petioles when they were grown in homogeneous treatments, irrespective of competition, but this was not the case when the plants were grown in heterogeneous treatments (significant heterogeneity $\times$ productivity interaction in Table 2 ; Fig. 5a). Plants from sites with higher mowing and grazing intensities produced longer petioles in the homogeneous competition-free treatment and in both heterogeneous treatments, but not in the homogeneous competition treatment (Table 2; Fig. 5b, c).

The average clonal foraging index, measured as the relative difference between the numbers of rooted rosettes in the two halves of each tray, was close to zero (Fig. 2e). It was not significantly affected by competition and heterogeneity, nor by any of the land-use variables (Table 2). 
Fig. 3 Fitted relationships between the number of rooted offspring ramets (vegetative reproduction) and a productivity, b mowing intensity, and c grazing intensity in the parental grassland site for $T$. repens plants in the four different competitive settings. The fitted relationships are derived from the generalized linear mixed model presented in Table 2, while fixing all other variables at their mean values. Gray shading indicates SE. Land-use variables were scaled to a mean of zero and a standard deviation of 1 (a) Productivity

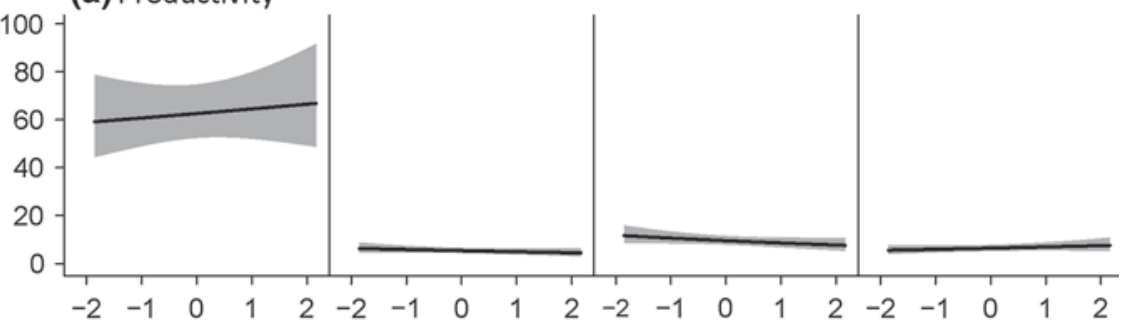

(b) Mowing intensity

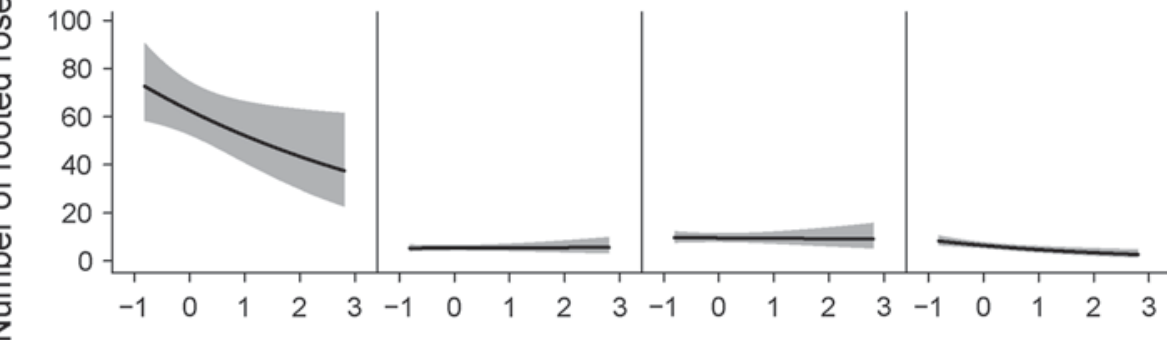

(c) Grazing intensity

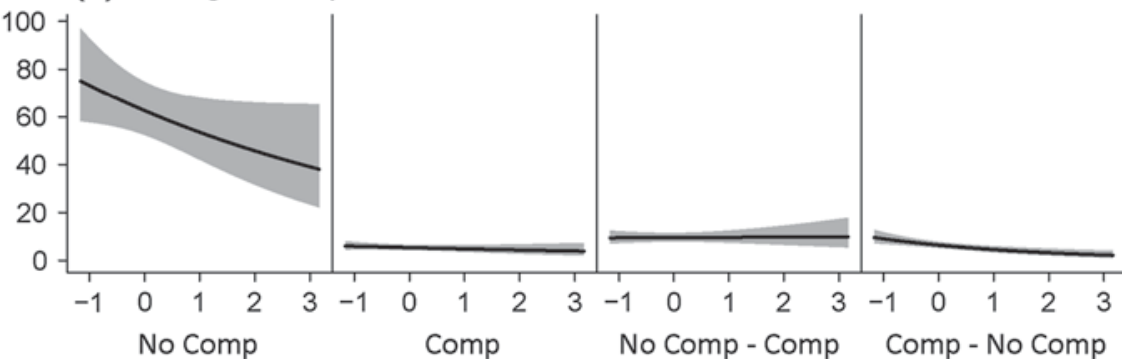

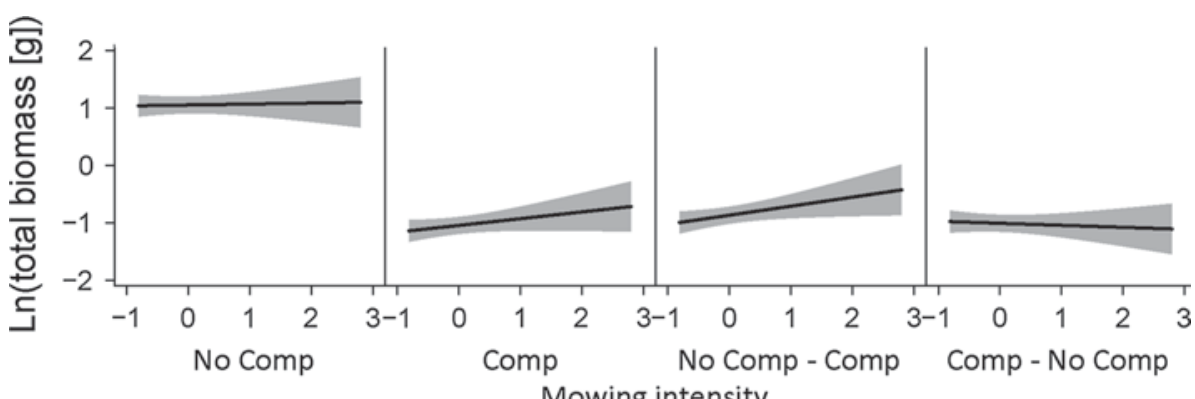

Mowing intensity

Fig. 4 Fitted relationships between the aboveground biomass and mowing intensity at the parental site for plants of $T$. repens in the four different competitive settings. The fitted relationships are derived from the linear mixed model presented in Table 2 while fixing

\section{Discussion}

We found strong direct effects of the presence of competitors on the morphology and performance of $T$. repens, with increases in petiole length, and reductions in growth, vegetative spread, and flowering. We also found evidence for effects of land-use intensity at the parental sites on morphology and performance of T. repens offspring. However, all other variables at their mean values. Gray shading indicates SE. Mowing intensity was scaled to a mean of zero and a standard deviation of 1

the expression or strength of these transgenerational effects depended on the growth environment.

\section{Performance of $T$. repens}

Flowering probability, vegetative reproduction, and aboveground biomass of $T$. repens were all strongly reduced by the presence of competitors in the trays. As the competitors 
Table 2 Results of linear mixed models for two measures of plasticity for plants of $T$. repens from grassland sites with different productivities and mowing and grazing intensities when growing under different competitive settings

\begin{tabular}{|c|c|c|c|c|c|}
\hline \multirow[t]{2}{*}{ Term } & \multirow[t]{2}{*}{$d f$} & \multicolumn{2}{|c|}{ Petiole length } & \multicolumn{2}{|c|}{ Foraging index } \\
\hline & & $\chi^{2}$ & $P$ & $\chi^{2}$ & $P$ \\
\hline \multicolumn{6}{|l|}{ Fixed } \\
\hline Initial leaf length & 1 & 26.61 & $<0.001$ & - & - \\
\hline Exploratory & 2 & 13.63 & 0.001 & 0.501 & 0.776 \\
\hline Productivity & 1 & 1.53 & 0.217 & 0.07 & 0.794 \\
\hline Mowing intensity & 1 & 12.52 & $<0.001$ & 0.01 & 0.912 \\
\hline Grazing intensity & 1 & 6.95 & 0.008 & 1.43 & 0.232 \\
\hline Competition treatment & 1 & 421.26 & $<0.001$ & 1.38 & 0.241 \\
\hline Heterogeneity treatment & 1 & 19.9 & $<0.001$ & 1.05 & 0.305 \\
\hline Comp $\times$ hetero & 1 & 57.111 & $<0.001$ & 3.71 & 0.054 \\
\hline Comp $\times$ explo & 2 & 0.15 & 0.927 & 4.17 & 0.124 \\
\hline Comp $\times$ prod & 1 & 0.72 & 0.395 & 0.28 & 0.595 \\
\hline Comp $\times$ mow & 1 & 7.5 & 0.006 & 0.96 & 0.328 \\
\hline Comp $\times$ graz & 1 & 8.54 & 0.003 & 2.81 & 0.094 \\
\hline Hetero $\times$ explo & 2 & 3.82 & 0.148 & 2.97 & 0.226 \\
\hline Hetero $\times$ prod & 1 & 10.89 & $<0.001$ & 2.2 & 0.138 \\
\hline Hetero $\times$ mow & 1 & 8.3 & $<0.001$ & 0 & 0.976 \\
\hline Hetero $\times$ graz & 1 & 2.46 & 0.117 & 1.46 & 0.228 \\
\hline Comp $\times$ hetero $\times$ explo & 2 & 1.82 & 0.402 & 0.28 & 0.87 \\
\hline Comp $\times$ hetero $\times$ prod & 1 & 0 & 0.98 & 0 & 0.976 \\
\hline Comp $\times$ hetero $\times$ mow & 1 & 1.49 & 0.222 & 0.73 & 0.392 \\
\hline Comp $\times$ hetero $\times$ graz & 1 & 2.64 & 0.104 & 2.69 & 0.101 \\
\hline \multicolumn{6}{|l|}{ Random } \\
\hline Block & & \multicolumn{2}{|l|}{0.123} & \multicolumn{2}{|c|}{$2.89 \times 10^{-4}$} \\
\hline Population & & \multicolumn{2}{|l|}{0.367} & \multicolumn{2}{|c|}{$6.07 \times 10^{-4}$} \\
\hline Seed family & & \multicolumn{2}{|l|}{1.04} & \multicolumn{2}{|c|}{$4.54 \times 10^{-3}$} \\
\hline Residual & & \multicolumn{2}{|l|}{6.239} & \multicolumn{2}{|c|}{$2.11 \times 10^{-1}$} \\
\hline
\end{tabular}

For the fixed terms, $\chi^{2}$ values are given based on log-likelihood ratio tests. For the random terms, variances are given

had been sown two months before the $T$. repens seedlings were planted (simulating the establishment of $T$. repens in an existing grassland), the competitors clearly had a priority effect (Morin 2011), and likely had depleted many of the available resources prior to the establishment of the $T$. repens seedlings. The strong reductions in performance of T. repens in the presence of competitors are in line with previous studies on this species (e.g., Solangaarachchi 1996; Weijschedé et al. 2008b). Our results and these previous ones therefore indicate that $T$. repens is a weak competitor or suffers strongly from prior resource depletion by competitors.

It was surprising that growth, vegetative reproduction, and flowering of $T$. repens plants were decreased to similar degrees in both tray halves of the heterogeneous treatment. This could suggest that the shading imposed by the competitors in the neighboring tray half was effectively equal to the shading in the tray half with competitors. However, petioles were slightly less elongated in the competitor-free tray halves than in the tray halves with competitors, which suggests that this was not the case. Another (more likely) explanation could be that the competitors had grown their roots into the competition-free halves, and had depleted the soil nutrients there to a similarly low level as in the tray halves with competitors. This suggests that the effect of competitors on belowground resource availability is at least as important as the effect on light availability.

In the absence of any competitors, T. repens from more productive sites tended to produce more vegetative offspring, suggesting that in more productive sites there has either been selection for genotypes of $T$. repens with more vegetative spread or that maternal carryover effects caused this pattern. As safe sites for recruitment from seeds in highly productive grasslands are limited (Eriksson and Ehrlén 1992; García-Fayos and Gasque 2006), it could be that the increase in vegetative reproduction with productivity reflects a trade-off between vegetative reproduction and seed production. However, as flowering probability did not differ between offspring from less and more productive sites, this seems unlikely. Moreover, a recent modeling study showed that increased clonal spread might actually contribute to dispersal, and therefore does not necessarily trade off with sexual fitness (Van Drunen et al. 2015).

Plants from more frequently mown and more intensively grazed sites, on the other hand, produced fewer vegetative offspring. Again, this could represent either genetic evolutionary change or maternal carryover effects, both of which could be adaptive. One possible adaptive explanation for this pattern is that spread through vegetative reproduction is only beneficial for plants in sites where plants and their stolons are less likely to get damaged by mowing and grazing. Another explanation could be that a small clone size might help plants to avoid detection by herbivores (Pluess 2013).

Flowering probability was not affected by the parental land-use variables, but aboveground biomass production tended to be higher for plants from more frequently mown sites. This effect, however, was only apparent in the homogeneous competition treatment and in the heterogeneous treatments where the mother ramets were planted in the competition-free half. Given that in the competition-free treatment there was a negative relationship between number of rooted rosettes and mowing frequency but no such a relationship for aboveground biomass, individual ramets must have been heavier when the plants originated from parental sites with a higher mowing frequency. This is also in line with the increase in petiole length with mowing frequency of the parental site. Mowing might select for genotypes of $T$. repens that can rapidly produce tall ramets, 
Fig. 5 Fitted relationships between petiole length of the longest leaf (a measure of vertical foraging) on the mother ramet and a productivity, $\mathbf{b}$ mowing intensity, and $\mathbf{c}$ grazing intensity of the parental grassland sites for T. repens plants in the four different competitive settings. The fitted relationships are derived from the linear mixed model presented in Table 1 while fixing all other variables at their mean values. Gray shading indicates SE. Land-use variables were scaled to a mean of zero and a standard deviation of 1

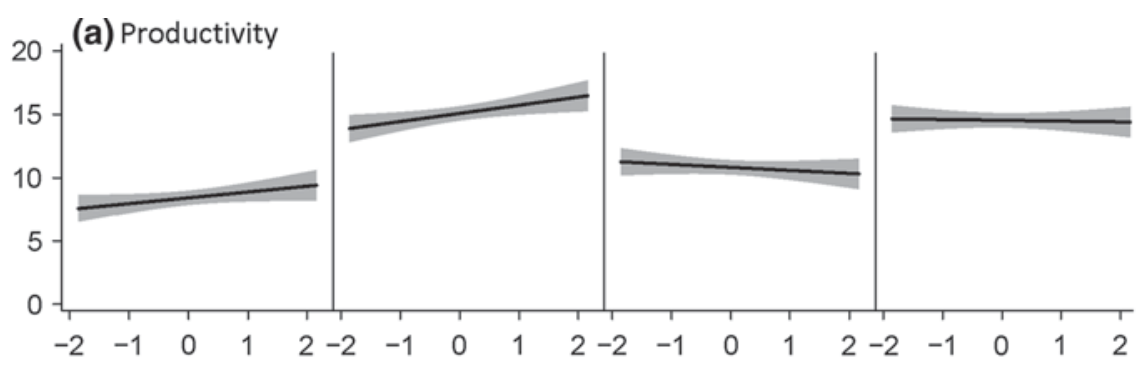

(b) Mowing intensity

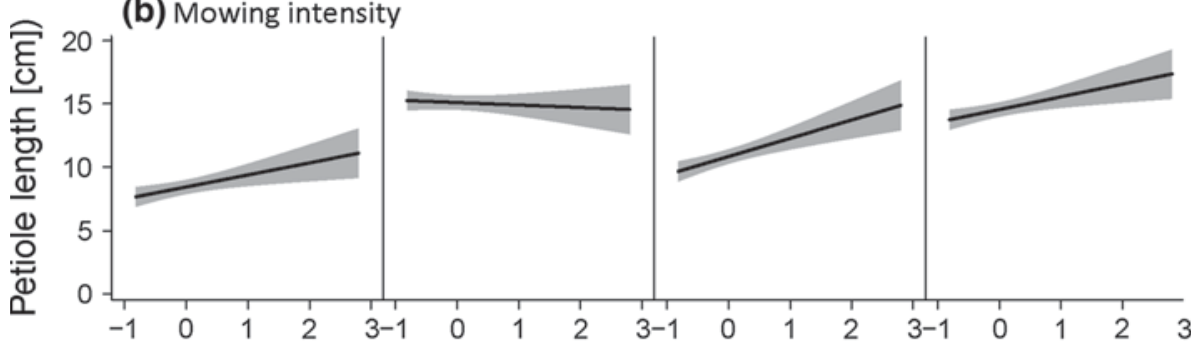

(c) Grazing intensity

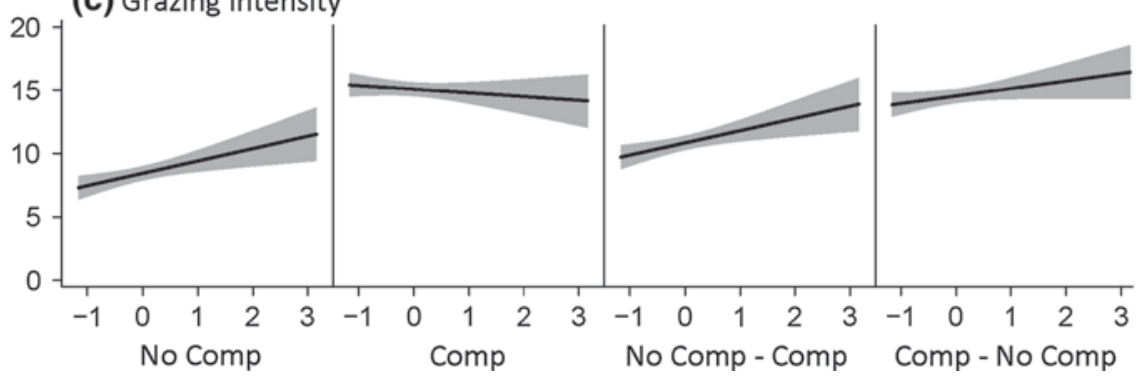

which can overtop neighboring plants directly after a mowing event.

\section{Vertical and horizontal foraging responses}

We did not find any evidence for selective ramet placement of $T$. repens when plants were grown in trays with heterogeneous competition. This suggests that $T$. repens is not capable of horizontal foraging by avoiding patches with competition or searching for competition-free patches. Given that the plants were planted in close proximity to the border between both patches, it is unlikely that the plants could not detect or reach the neighboring patches. Previous studies that tested for foraging responses in $T$. repens by measuring stolon internode elongation also did not find any strong foraging responses; some studies found that it tended to shorten stolon internodes under shading (Solangaarachchi and Harper 1987; Thompson and Harper 1988; Caradus and Chapman 1991; Thompson 1993), while others found the opposite response (Solangaarachchi and Harper 1987; Thompson 1993; Macek and Lepš 2003) or no significant response at all (Huber et al. 1998; Marcuvitz and Turkington 2000). T. repens also showed variable internode responses with regard to increased nutrient levels. One study found internode shortening (Hutchings et al.
1997) but others found internode elongation (Caradus et al. 1993; Lotscher and Hay 1997) or no response at all (Nie et al. 1998). In our study, the initial internodes produced by the plants were very short $(<1 \mathrm{~cm})$, which would have made effects of plastic elongation responses or selective ramet placement negligible. Moreover, the plants produced slightly shorter instead of longer stolons when competitors were present (results not shown). Thus, overall, it appears that horizontal foraging responses in T. repens are limited. This supports the idea of de Kroon and Hutchings (1995) that most of the plastic changes in internode length are insufficient to elicit a significant concentration of ramets in favorable habitat patches.

Because changes in light intensity in the vertical plane are more predictable than changes in the horizontal plane, it has been suggested that orthotropic plant organs (i.e., vertically oriented stems or leaves) are generally more plastic in response to shading than plagiotropic plant organs (i.e., horizontally oriented stems or leaves; de Kroon and Hutchings 1995; Huber 1996; Huber et al. 1998). Indeed, in the vertical direction, $T$. repens showed strong petiole elongation when grown in tray halves with competition or in close proximity to competitors. As the sward of competitors was only c. $10-15 \mathrm{~cm}$ high, this elongation effectively positioned the trifoliate leaf blades of $T$. repens in 
the top layer of the sward or even above it (Z. Wang and M. van Kleunen, personal observation). Previous studies of T. repens reported similar petiole-elongation responses to shading (Huber et al. 1998; Weijschedé et al. 2006, 2008a, b). Such shade-avoidance responses are also frequently reported for other species when they experienced intraspecific (Vermeulen and During 2010) or interspecific competition (Barthram 1997; van Kleunen and Fischer 2001; Weijschedé et al. 2008b). Our findings of strong petiole plasticity but no horizontal foraging thus provide more support for the idea that orthotropic plant organs are generally more plastic in response to shading than plagiotropic ones.

Plants from more productive sites produced longer petioles than the ones from less productive sites when they grew in one of the homogeneous treatments, with or without competition. As more productive sites usually have taller vegetation, it is likely that plants of $T$. repens with long petioles, which position the leaf laminas in the upper layers of the vegetation, have an advantage. Although it is not clear why this pattern was not present when plants were grown in the heterogeneous treatments, our results suggest that plants from more productive sites have undergone adaptive evolution towards longer petioles or that adaptive maternal carryover effects are responsible for this pattern.

While all plants produced long petioles in the homogeneous competition treatment, irrespective of the mowing and grazing intensities of their parental sites, petiole lengths increased with the mowing and grazing intensities at the parental sites in all other treatments, i.e., the homogeneous competition-free and the heterogeneous treatments. In other words, plants from sites with high mowing and grazing intensities more or less consistently produced long petioles, whereas plants from sites with low mowing and grazing intensities were able to reach similar petiole lengths under homogeneous competition by means of plasticity. The underlying cause of this difference in plasticity might be that high mowing and grazing intensities can result in a more homogeneous vegetation cover. While livestock might increase heterogeneity, the presence of many livestock may result in grazing to very short sward heights, thereby reducing grassland heterogeneity. Indeed, there is evidence that livestock grazing can, under certain conditions, homogenize soils in grasslands (Adler et al. 2001; Hirobe et al. 2013). Whatever the exact reason, our results show that land-use intensity can affect the phenotypic plasticity of the offspring.

\section{Conclusions}

Plants of T. repens in our study did not show any evidence of horizontal foraging, but they did show strong vertical foraging by means of petiole elongation when grown either directly among or in close proximity to competitors. Flowering probability, vegetative reproduction and aboveground biomass of $T$. repens were all strongly reduced by the presence of competitors in the trays, even when the mother ramets had been planted in the competition-free halves of the trays. Overall, this shows that there are strong effects of neighbors, due to either prior belowground resource depletion or direct competition, on the morphology and performance of T. repens.

Petiole length and the number of vegetative offspring were related to productivity, mowing frequency, and grazing intensity in the parental sites, but these transgenerational effects were expressed in only some of the experimental treatments. Although we cannot distinguish between maternal environmental carryover effects (Roach and Wulff 1987), epigenetic mechanisms (Bossdorf et al. 2008), and evolutionary change, our results indicate that land use not only has a direct effect on plants but also affects their offspring.

Acknowledgments We thank Eva Völler and Harald Auge for collecting the seeds, and Yuanye Zhang, Lidewij Keser, Anne Kempel, Andreas Ensslin, Gemma Rutten, Yvonne Zürcher, Joël Baumann, and Michael Moser for help with the harvesting. ZW and MvK acknowledge the support of the Sino-Swiss Science and Technology Cooperation (EG 14-092009). We thank the managers of the three Exploratories-Swen Renner, Sonja Gockel, Kerstin Wiesner, and Martin Gorke-for their work in maintaining the plot and project infrastructure; Simone Pfeiffer and Christiane Fischer for providing support through the central office, Michael Owonibi for managing the central database, and Eduard Linsenmair, Dominik Hessenmöller, Jens Nieschulze, Ingo Schöning, François Buscot, Ernst-Detlef Schulze, Wolfgang W. Weisser, and the late Elisabeth Kalko for their role in setting up the Biodiversity Exploratories project. The work has been partly funded by the DFG Priority Program 1374 "Infrastructure-Biodiversity-Exploratories" and NSFC grants (41371077, 31570530). The experiment complies with the current laws of Switzerland (the country in which the experiment was performed).

Author contribution statement All authors together conceived and designed the experiment. ZW and MVK performed the experiment. MVK analyzed the data. OB, MF and DP provided seed materials and data on land use intensities. ZW and MVK wrote the manuscript, with comments and help from the other authors.

\section{Compliance with ethical standards}

Conflict of interest The authors declare that they have no conflict of interest.

\section{References}

Aasmo Finne M, Rognli OA, Schjelderup I (2000) Genetic variation in a Norwegian germplasm collection of white clover (Trifolium repens L.) 1. Population differences in agronomic characteristics. Euphytica 112:33-44

Adler PB, Raff DA, Lauenroth WK (2001) The effect of grazing on the spatial heterogeneity of vegetation. Oecologia 128:465-479 
Augustine DJ, Frank DA (2001) Effects of migratory grazers on spatial heterogeneity of soil nitrogen properties in a grassland ecosystem. Ecology 82:3149-3162

Bakker C, Blair JM, Knapp KA (2003) Does resource availability, resource heterogeneity or species turnover mediate changes in plant species richness in grazed grasslands? Oecologia $137: 385-391$

Barthram GT (1997) Shoot characteristics of Trifolium repens grown in association with Lolium perenne or Holcus lanatus in pastures grazed by sheep. Grass Forage Sci 52:336-339

Bates RO, Doumit ME, Raney NE, Helman EE, Ernst CW (2012) Association of halothane sensitivity with growth and meat quality in pigs. Animal 6:1537-1542

Berner D, Marhan S, Keil D, Poll C, Schutzenmeister A, Piepho HP, Kandeler E (2011) Land-use intensity modifies spatial distribution and function of soil microorganisms in grasslands. Pedobiologia 54:341-351

Bittebiere A-K, Renaud N, Clément B, Mony C (2012) Morphological response to competition for light in the clonal Trifolium repens (Fabaceae). Am J Bot 99:646-654

Blüthgen N, Dormann CF, Prati D, Klaus VH, Kleinebecker T, Hölzel N, Alt F, Boch S, Gockel S, Hemp A (2012) A quantitative index of land-use intensity in grasslands: integrating mowing, grazing and fertilization. Basic Appl Ecol 13:207-220

Bossdorf O, Richards CL, Pigliucci M (2008) Epigenetics for ecologists. Ecol Lett 11:106-115

Caradus JR, Chapman DF (1991) Variability of stolon characteristics and response to shading in two cultivars of white clover (Trifolium repens L.). New Zeal J Agr Res 34:239-247

Caradus JR, Hay HJM, Mackay AD, Thomas VJ, Dunlop J, Lambert MG, Hart AL, Vandenbosch J, Wewala S (1993) Variation within white clover (Trifolium repens L.) for phenotypic plasticity of morphological and yield related characters, induced by phosphorus supply. New Phytol 123:175-184

de Kroon H, Bobbink R (1997) Clonal plant dominance under elevated nitrogen deposition, with special reference to Brachypodium pinnatum in chalk grassland. In: de Kroon $\mathrm{H}$, van Groenendael J (eds) The ecology and evolution of clonal plants. Backhuys, Leiden, pp 359-379

de Kroon H, Hutchings HJ (1995) Morphological plasticity in clonal plants: the foraging concept reconsidered. J Ecol 83:143-152

Eriksson O, Ehrlén J (1992) Seed and microsite limitation of recruitment in plant populations. Oecologia 91:360-364

Fischer M, van Kleunen M (2002) On the evolution of clonal plant life histories. Evol Ecol 15:565-582

Fischer M, Bossdorf O, Gockel S, Hänsel F, Hemp A, Hessenmöller D, Korte G, Nieschulze J, Pfeiffer S, Prati D (2010) Implementing large-scale and long-term functional biodiversity research: the Biodiversity Exploratories. Basic Appl Ecol 11:473-485

García-Fayos P, Gasque M (2006) Seed vs. microsite limitation for seedling emergence in the perennial grass Stipa tenacissima $\mathrm{L}$. (Poaceae). Acta Oecol 30:276-282

Hirobe M, Kondo J, Enkhbaatar A, Amartuvshin N, Fujita N, Sakamoto K, Yoshikawa K, Kielland K (2013) Effects of livestock grazing on the spatial heterogeneity of net soil nitrogen mineralization in three types of Mongolian grasslands. J Soil Sediment 13:1123-1132

Howe HF (1999) Dominance, diversity and grazing in tallgrass restoration: ecology has much to contribute to debates over the role of grazing in restoration - and much to learn from the results of experiments in restorative grazing. Ecol Restor 17:59-66

Huber H (1996) Plasticity of internodes and petioles in prostrate and erect Potentilla species. Funct Ecol 10:401-409

Huber H, Fijan A, During HJ (1998) A comparative study of spacer plasticity in erect and stoloniferous herbs. Oikos 81:576-586
Huber H, Jacobs E, Visser EJW (2009) Variation in flooding-induced morphological traits in natural populations of white clover (Trifolium repens) and their effects on plant performance during soil flooding. Ann Bot 103:377-386

Hutchings MJ, Wijesinghe DK (2008) Performance of a clonal species in patchy environments: effects of environmental context on yield at local and whole-plant scales. Evol Ecol 22:313-324

Hutchings MJ, Turkington R, Carey P, Klein E (1997) Morphological plasticity in Trifolium repens L.: the effects of clone genotype, soil nutrient level, and the genotype of conspecific neighbours. Can J Bot 75:1382-1393

Johansen L (2009) Clonal growth strategies in simultaneously persistent and expanding Trifolium repens patches. Plant Ecol 201:435-444

Klimeš L, Klimešová J, Hendriks R, van Groenendael J (1997) Clonal plant architecture: a comparative analysis of form and function. In: de Kroon H, van Groenendael J (eds) The ecology and evolution of clonal plants. Backhuys Publishers, Leiden, pp 1-29

Lotscher M, Hay MJM (1997) Genotypic differences in physiological integration, morphological plasticity and utilization of phosphorus induced by variation in phosphate supply in Trifolium repens. J Ecol 85:341-350

Macek P, Lepš J (2003) The effect of environmental heterogeneity on clonal behaviour of Prunella vulgaris L. Plant Ecol 168:31-43

Marcuvitz S, Turkington R (2000) Differential effects of light quality, provided by different grass neighbours, on the growth and morphology of Trifolium repens L. (white clover). Oecologia 125:293-300

Marion B, Bonis A, Bouzillé J-B (2010) How much does grazinginduced heterogeneity impact plant diversity in wet grasslands? Ecoscience 17:229-239

Morin PJ (2011) Community ecology. Wiley-Blackwell, Malden

Nie ZN, Barker DJ, Mackay AD, Valentine I, Hodgson J (1998) Influence of the timing and duration of pastoral fallowing and nitrogen fertiliser on pasture and white clover (Trifolium repens) growth in hill country. New Zeal J Agr Res 41:19-29

Pluess AR (2013) Meta-analysis reveals microevolution in grassland plant species under contrasting management. Biodivers Conserv 22:2375-2400

R Development Core Team (2012) R: a language and environment for statistical computing. R Foundation for Statistical Computing, Vienna

Roach DA, Wulff RD (1987) Maternal effects in plants. Ann Rev Ecol Syst 18:209-235

Schielzeth H (2010) Simple means to improve the interpretability of regression coefficients. Methods Ecol Evol 1:103-113

Socher AA, Prati D, Boch S, Müller J, Klaus VH, Hölzel N, Fischer M (2012) Direct and productivity-mediated indirect effects of fertilization, mowing, and grazing on grassland species richness. J Ecol 100:1391-1399

Solangaarachchi SM (1996) The influence of neighbouring grasses on the growth of white clover (Trifolium repens L.). J Natl Sci Found Sri Lanka 24:95-110

Solangaarachehi SM, Harper JL (1987) The effect of canopy filtered light on the growth of white clover Trifolium repens. Oecologia 72:372-376

Thompson L (1993) The Influence of natural canopy density on the growth of white clover, Trifolium repens. Oikos 67:321-324

Thompson L, Harper JL (1988) The effect of grasses on the quality of transmitted radiation and its influence on the growth of white clover Trifolium repens. Oecologia 75:343-347

Van Drunen WE, van Kleunen M, Dorken M (2015) Consequences of clonality for sexual fitness: clonal expansion enhances fitness under spatially restricted dispersal. Proc Natl Acad Sci USA 112(29):8929-8936. doi: 10.1073/pnas.1501720112 
van Kleunen M, Fischer M (2001) Adaptive evolution of plastic foraging responses in a clonal plant. Ecology 82:3309-3319

van Kleunen M, Fischer M, Schmid B (2000) Clonal integration in Ranunculus reptans: by-product or adaptation? J Evol Biol 13:237-248

Vermeulen PJ, During HJ (2010) Genotype-density interactions in a clonal, rosette-forming plant: cost of increased height growth? Ann Bot 105:79-88

Vermeulen PJ, Anten NPR, Schieving F, Werger MJA, During HJ (2008) Height convergence in response to neighbour growth: genotypic differences in the stoloniferous plant Potentilla reptans. New Phytol 177:688-697

Völler E, Auge H, Prati D, Fischer M, Hemp A, Bossdorf O (2012) Geographical and land-use effects on seed-mass variation in common grassland plants. Basic Appl Ecol 13:395-404

Wang ZW, van Kleunen M, During HJ, Werger MJA (2013) Root foraging increases performance of the clonal plant Potentilla reptans in heterogeneous nutrient environments. PLoS One 8:e58602

Weijschedé J, Martínková J, de Kroon H, Huber H (2006) Shade avoidance in Trifolium repens: costs and benefits of plasticity in petiole length and leaf size. New Phytol 172:655-666
Weijschedé J, Antonise $\mathrm{K}$, de Caluwe $\mathrm{H}$, de Kroon H, Huber $\mathrm{H}$ (2008a) Effects of cell number and cell size on petiole length variation in a stoloniferous herb. Am J Bot 95:41-49

Weijschedé J, Berentsen R, de Kroon H, Huber H (2008b) Variation in petiole and internode length affects plant performance in Trifolium repens under opposing selection regimes. Evol Ecol 22:383-397

Wijesinghe DK, Hutchings MJ (1997) The effects of spatial scale of environmental heterogeneity on the growth of a clonal plant: an experimental study with Glechoma hederacea. J Ecol 85:17-28

Zhou ZY, Sun OJ, Luo ZK, Jin HM, Chen QS, Han XG (2008) Variation in small-scale spatial heterogeneity of soil properties and vegetation with different land use in semiarid grassland ecosystem. Plant Soil 310:103-112

Zuur AF, Ieno EN, Walker NJ, Saveliev AA, Smith GM (2009) Mixed effects models and extensions in ecology with R. Springer, New York

Zuur AF, Saveliev AA, Ieno EN (2012) Zero inflated models and generalized linear mixed models with R. Highland Statistics Ltd, Newburgh 